\title{
Experimental and numerical analysis of Al6063 duralumin using Taylor impact test
}

\author{
L. Kruszka, Ł. Anaszewicz, J. Janiszewski, and M. Grązka \\ Gen. Jaroslaw Dabrowski Military University of Technology, 2, Gen. Sylwester Kaliski st., 00-908 Warsaw, \\ Poland
}

\begin{abstract}
The paper presents results of experimental and numerical analysis of dynamic behaviour Al6063 duralumin. Dynamical experiments were made using Taylor impact test. Experimental results at next step of study were used in numerical analyses of dynamic yield stress of tested material and model parameters of the Johnson-Cook constitutive equation. The main aim of this analysis is to find out dynamical properties of Al6063 duralumin tested in Taylor impact test.
\end{abstract}

\section{Introduction}

Al6063 aluminum alloy is very popular structural material in many civil engineering applications. Al6063 duralumin has been also used as a bracket in airplanes, cars and architecture constructions. It has been a part of new design and manufacture windows or doors, including for example protective facades.

Taylor impact test was applied in order to determine the mechanical properties of Al6063 duralumin at high strain rates. Figure 1 shows the idea scheme of Taylor impact test. The equation (1) is used in engineering calculations of dynamic yield stress $Y$. Using this equation we need know some information on the geometry of specimen before and after dynamical deformation process. The overall length of specimen $L$, the impact velocity $V$, the length of nondeformed part of specimen $l_{f}$, and the density of material tested are necessary data, which we have to know in order to calculate the dynamic yield stress $Y$. These information we also have to know during identification process of constants at Johnson-Cook empirical constitutive equation. All these data were made from speed movie analyses and from the geometry of specimen scanned after the Taylor impact test using the coordinate measure method.

$$
Y=\frac{\frac{1}{2} \cdot \rho \cdot V^{2} \cdot\left(1-\frac{l_{f}}{L}\right)}{\left(1-\frac{L_{f}}{L}\right) \cdot \ln \left(\frac{L}{l_{f}}\right)}
$$

where:

- $\rho$ - density of tested material;

- $\mathbf{v}$ - impact velocity of specimen;

- $\mathbf{l}_{f}$ - length of non-deformed part of specimen;

- L- overall length of specimen;

- $\mathbf{L}_{f^{-}}$length of deformed specimen.

The main aim of presented paper is to determine dynamic yield stress and calculated constants of Johnson Cook equation for $\mathrm{Al}$ 6063aluminum alloy.

\section{Experimental set-up}

The experimental investigation of dynamical mechanical properties of Al6063 duralumin at strain rates of $5 \cdot 10^{3} 1 / \mathrm{s}$ were performed using the experimental set-up presented in Figure 2. This apparatus to conduct Taylor impact test consists of apyrotechnic launching system, a maraging steel target plate with polished surfaces, and the recording system, which is composed of a high-speed camera and a system of lighting research space.

Cylindrical specimens were machined from the Al6063 duralumin bar of $15 \mathrm{~mm}$ in diameter. The staticstandardized properties of tested aluminium alloy are presented in Table 1 . The overall dimensions of cylindrical specimens were $8 \mathrm{~mm} \times 56 \mathrm{~mm}$.

Experimental and numerical analyses were conducted for seven specimens of Al6063 duralumin. The geometry and mass data of those specimens before impact experiments are given in Table 2.

Specimens were tested with impact velocity between $170 \mathrm{~m} / \mathrm{s}$ and $220 \mathrm{~m} / \mathrm{s}$. Various impact velocity of specimens was necessary to has broad spectrum of deformation information. Figure 3 shows sequential images from some impact experiment with the impact velocity of $190 \mathrm{~m} / \mathrm{s}$.

In Figure 3 we can see how visible radial deformation of Al6063 was being propagated along specimen. Next Figure 4 shows pictures of some specimen before and after the impact experiment. We can see there, that duralumin specimen is deformed in typical way for Taylor impact test. The character of this deformation is connect with high toughness of this material.

\section{Experimental results and discussion}

After Taylor impact experiment all deformed specimens were check. During this inspection one specimen No. 2 was cracked at impacted end, so we didn't take it to next step of analyses. Remaining specimens were measured using the coordinate measure method (CMM) [1]. On this base profiles and final lengths of specimens after impact deformation were determined in order to calculate dynamic yield stresses using the equation (1). Results of those calculations are shown in Table 3.

Taylor suggested using the correction factor for exact calculations of dynamic yield stresses [3]. We can obtain this correction factor from the diagrams which was prepared for this aim (see Figure 5). If we want choose the 
a)

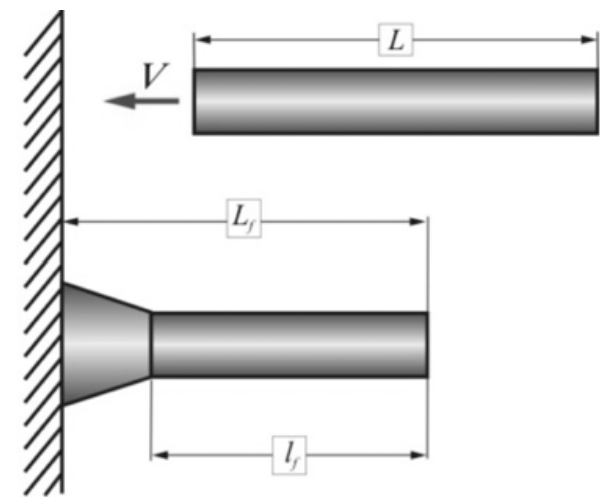

Fig. 1. Schema of Taylor impact test: a) specimen before the impact; b) specimen after the impact test.

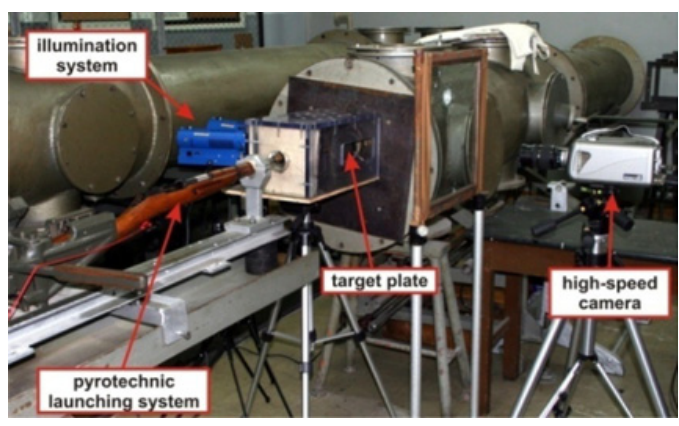

Fig. 2. View of the arrangement for Taylor impact test.

Table 1. Mechanical static properties of the Al 6063 duralumin according to Polish Standard.

\begin{tabular}{|c|c|c|c|c|c|}
\hline $\begin{array}{c}\text { Tensile } \\
\text { strength }\end{array}$ & $\begin{array}{c}\text { Elon- } \\
\text { gation } \\
\mathrm{A}_{50 \mathrm{~mm}}\end{array}$ & $\begin{array}{c}\text { Elon- } \\
\text { gation }\end{array}$ & $\begin{array}{c}\text { Yield } \\
\text { Stress }\end{array}$ & $\begin{array}{c}\text { Hard- } \\
\text { ness }\end{array}$ & $\begin{array}{c}\text { Tough- } \\
\text { ness }\end{array}$ \\
\hline $\begin{array}{c}215 \mathrm{~N} / \mathrm{mm}^{2} \\
\mathrm{~N} / \mathrm{mm}^{2}\end{array}$ & $8 \%$ & $6 \%$ & $\begin{array}{c}170 \mathrm{~N} / \mathrm{mm}^{2} \\
\mathrm{~N} / \mathrm{mm}^{2}\end{array}$ & $\begin{array}{c}37 \mathrm{HB} \\
37 \mathrm{HB}\end{array}$ & $\begin{array}{c}24 \mathrm{~J} \\
24 \mathrm{~J}\end{array}$ \\
\hline
\end{tabular}

Table 2. Data of geometric parameters tested specimens.

\begin{tabular}{|c|c|c|c|c|c|c|c|}
\hline $\begin{array}{c}\text { Signature of } \\
\text { specimen }\end{array}$ & $\begin{array}{c}\text { No. } \\
1\end{array}$ & $\begin{array}{c}\text { No. } \\
2\end{array}$ & $\begin{array}{c}\text { No. } \\
3\end{array}$ & $\begin{array}{c}\text { No. } \\
4\end{array}$ & $\begin{array}{c}\text { No. } \\
5\end{array}$ & $\begin{array}{c}\text { No. } \\
6\end{array}$ & $\begin{array}{c}\text { No. } \\
7\end{array}$ \\
\hline $\begin{array}{c}\text { Diameter } \\
{[\mathrm{mm}]}\end{array}$ & 7,96 & 7,94 & 7,96 & 7,96 & 7,96 & 7,96 & 7,93 \\
\hline $\begin{array}{c}\text { Length } \\
{[\mathrm{mm}]}\end{array}$ & 55,9 & 56,0 & 55,9 & 56,0 & 55,9 & 56,0 & 56,0 \\
\hline Mass [g] & 7,51 & 7,48 & 7,47 & 7,50 & 7,51 & 7,51 & 7,47 \\
\hline
\end{tabular}

correction factor we should calculate two values: first as the ratio of the length non-deformed part of specimens to the length of specimens before deformation $\left(l_{f} / L\right)$, second as the ratio of overall length of specimens before and after deformation $\left(L_{f} / L\right)$. If we have these values we could choose correction curve in Figure 5 in order to obtain the correction factor. At next step we took the value of dynamic yield stress calculated using equation (1) and it multiplies with correction factor value from the curve.

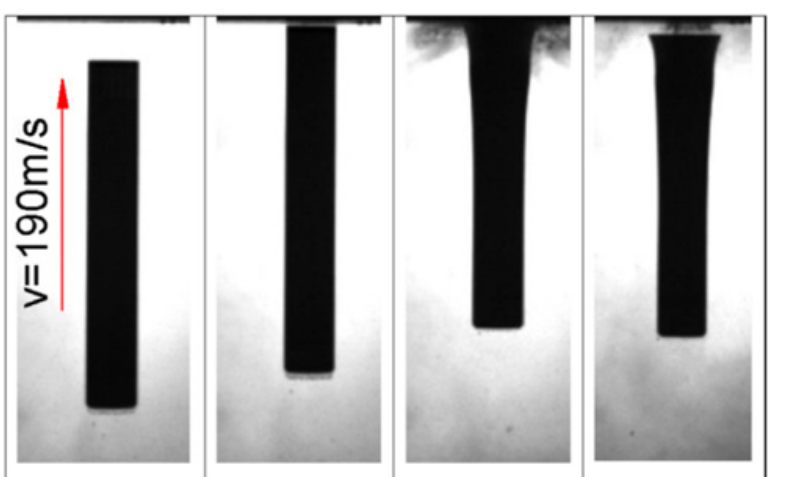

Fig. 3. Sequential images obtained from dynamical process of specimen deformation during Taylor impact test.

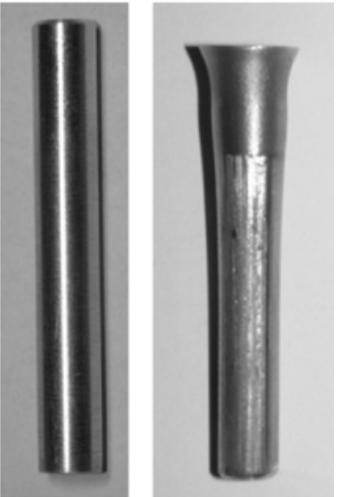

Fig. 4. View of some specimen before and after the experiment at impact velocity $\mathrm{v}=187,7 \mathrm{~m} / \mathrm{s}$.

Table 3. Dynamic yield stresses calculated for all tested specimens.

\begin{tabular}{|c|c|}
\hline Number of specimen & Dynamic yield stress $Y[\mathrm{MPa}]$ \\
\hline No. 1 & 205 \\
\hline No. 3 & 176 \\
\hline No. 4 & 230 \\
\hline No. 5 & 201 \\
\hline No. 6 & 176 \\
\hline No. 7 & 199 \\
\hline Average & 198 \\
\hline
\end{tabular}

New corrected values of dynamic yield stress $S$ are shown in Table 4. These values were calculated using correct factor and the strain rate was between $10^{3} \div 10^{4} 1 / \mathrm{s}$.

Above calculated values of corrected dynamic yield stresses aren't describing enough behavior of tested materials under dynamic deformation at strain rates of $10^{3} 1 / \mathrm{s}$ and larger. Now we analyze more than only dynamic yield stresses, including some constitutive relation, for example Johnson-Cook equation.

$$
\sigma=\left(A+B \varepsilon^{n}\right)\left(1+C \ln \frac{\dot{\varepsilon}}{\dot{\varepsilon}_{0}}\right)\left[1-\left(\frac{T-T_{0}}{T_{m}-T}\right)^{m}\right]
$$




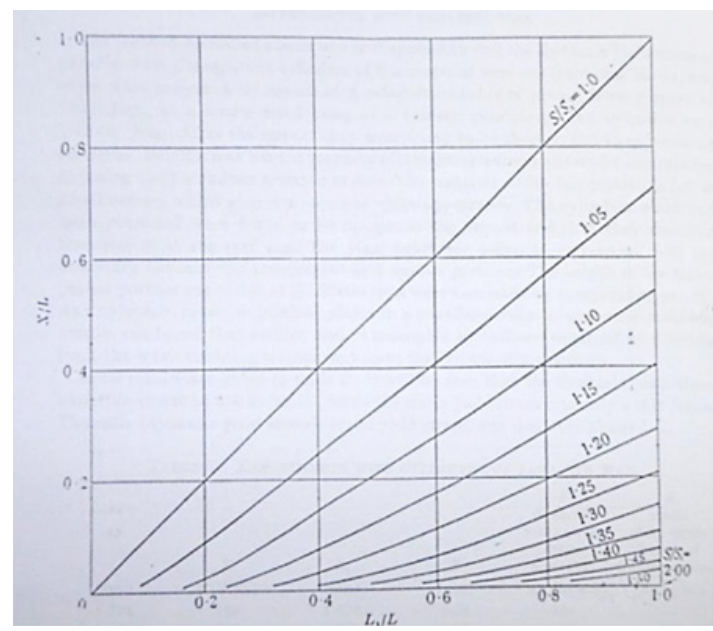

Fig. 5. Graphs of correction factor curves [3].

Table 4. Corrected dynamic yield stresses.

\begin{tabular}{|c|c|}
\hline Number of specimens & Dynamic yield stress $S[\mathrm{MPa}]$ \\
\hline No. 1 & 232 \\
\hline No. 3 & 217 \\
\hline No. 4 & 260 \\
\hline No. 5 & 231 \\
\hline No. 6 & 215 \\
\hline No. 7 & 229 \\
\hline Average & 231 \\
\hline
\end{tabular}

This equation is very popular and easy to use in numerical simulations. We were used results of Al6063 specimens' deformation in order to find model constants of Johnson-Cook equation. Those constants were determined by numerical analyses using the Autodyn solver as well as the Autodyn and Multi Objective Genetic identification Algorithm (MOGA) to solve an inverse problem of impact deformation. Figure 6 shows the procedure scheme of used so called identification algorithm.

Numerical simulation of Taylor impact test and results of this simulation was used to calculate constants of Johnson-Cook equation in the identification process, which was finished when the geometric dimensions and the impact velocity of specimen obtained from the computer simulation, were the same as from impact experiment. We assumed specimen was deformable and target plate was rigid. FEM method was used to simulate impact deformation by the Autodyn solver. Type of elements was hexagonal with eight nodes and one point of integration. Figure 7 shows two pictures of some specimen before and after impact deformation at the impact velocity $(\mathrm{v}=$ $187.7 \mathrm{~m} / \mathrm{s}$ ) from the numerical analyses.

Model of specimen was divided into one quarter in order the simulation process of Taylor impact test was more effective. We assumed the contact between head of the specimenand target was without friction during radial deformation, because earlier results of such computer simulations for checking the influence of friction between

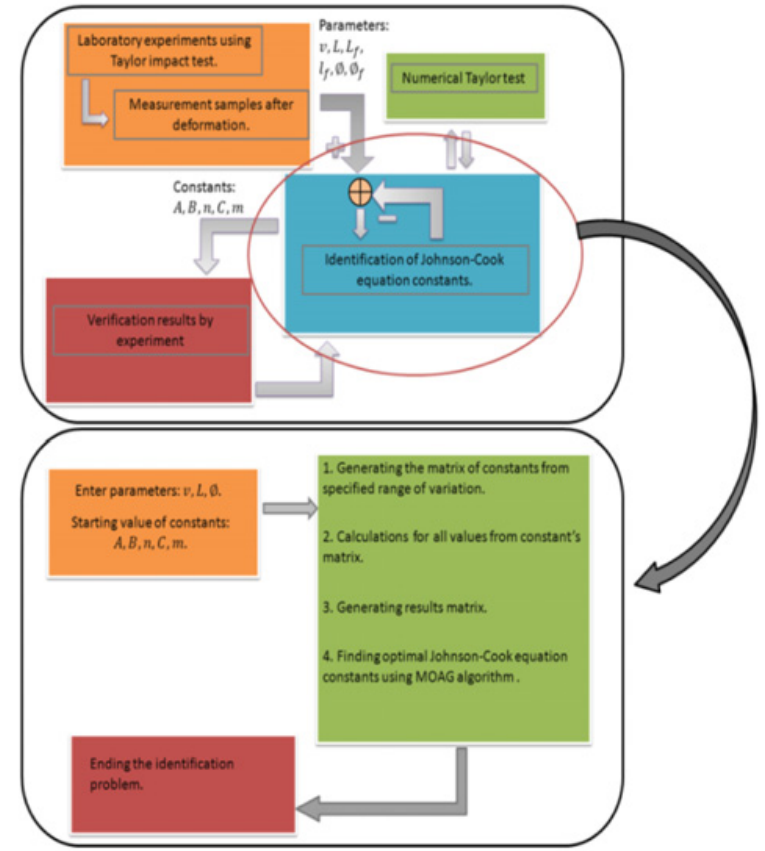

Fig. 6. Scheme of identification algorithm used in numerical analyses.
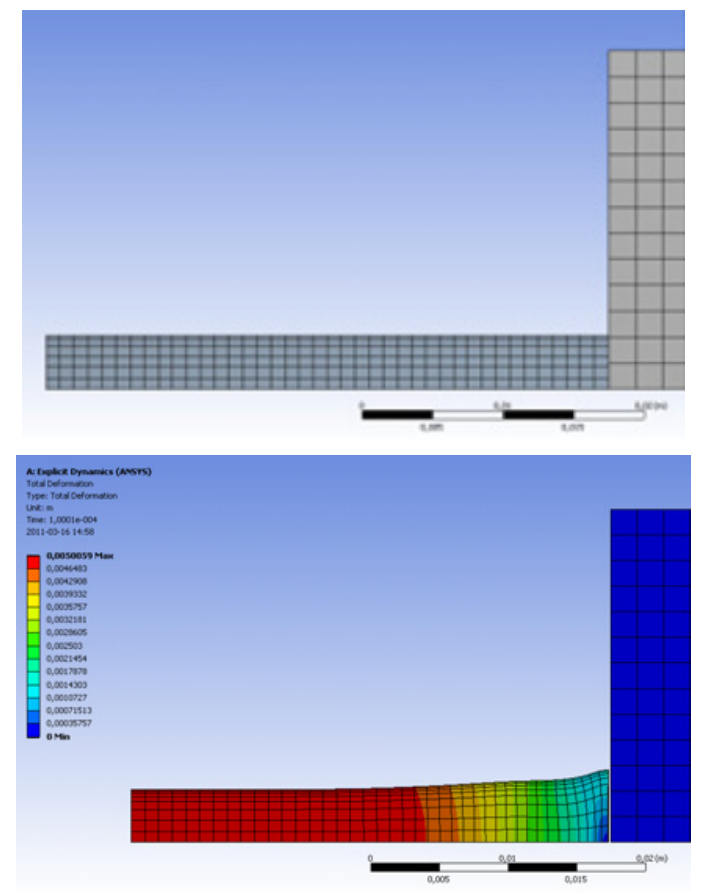

Fig. 7. Profiles of specimen with the mesh grid before and after the impact deformation at $\mathrm{v}=187,7 \mathrm{~m} / \mathrm{s}$.

specimens and target, demonstrated that phenomenon of the friction didn't haveessential influences on obtained results. The friction factor was small (was used 0.1 and 0.2 ) because during experiments surface of target was lubricated.

We determined five unknown values as constants of Johnson-Cook equation during the identificationprocess. All those constants were calculated by the multi objective genetic algorithm with an objective function. The objective 
Table 5. Values of Johnson-Cook constants calculated for Al6063 duralumin.

\begin{tabular}{|c|c|c|c|c|c|c|c|}
\hline No. of specimen/ parameter & 1 & 3 & 4 & 5 & 6 & 7 & Average \\
\hline A & 128,3 & 102,0 & 100,4 & 108,8 & 105,6 & 125,8 & 111,8 \\
\hline B & 200,9 & 261,7 & 259,4 & 243,6 & 394,2 & 268,9 & 241,4 \\
\hline $\mathrm{n}$ & 0,47 & 0,25 & 0,48 & 0,49 & 0,40 & 0,40 & 0,415 \\
\hline $\mathrm{C}$ & 0,0086 & 0,0112 & 0,0142 & 0,0084 & 0,0174 & 0,0158 & 0,0120 \\
\hline $\mathrm{m}$ & 0,98 & 1,05 & 0,99 & 0,85 & 1,13 & 1,02 & 1,003 \\
\hline
\end{tabular}

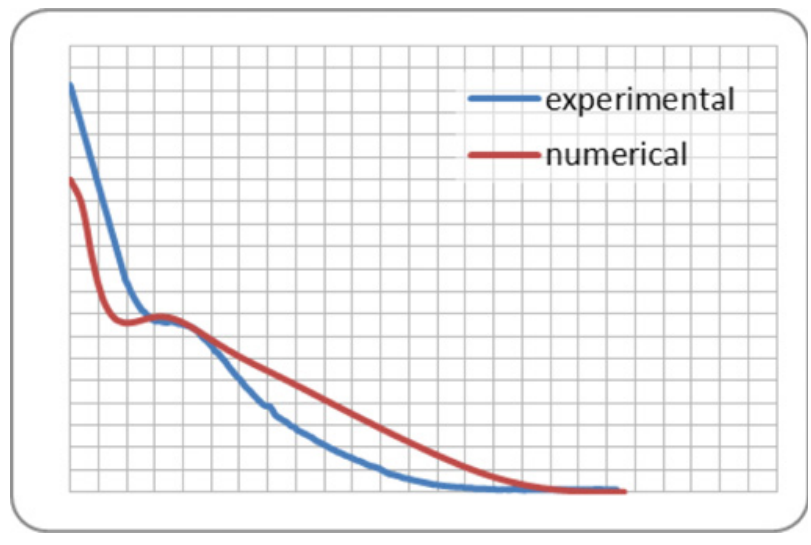

Fig. 8. Comparison of specimen profiles obtained from numerical and experimental analysis.

function was prepared as follows: the aim of calculation was found the minimum error sum of parameters such as the diameter in head of specimen, the length of deformed part and the length of specimen after impact deformation. The identification process was done by the iteration calculation and one by one iteration when the error of objective function was minimized. Results of the identification process of Johnson-Cooke equation constants for Al6063duralumin are presented in Table 5.

Finally, all determined constants have been analyzed in order to check whether they are correctly enumerated. At this checking procedure, first error of the objective function was found for example for differences between the length of specimens after the impact experiment and the calculated length from the computer simulation. Next, determined constants were compared for specimen's profiles received from numerical and experimental studies. Figure 8 shows experimental and numerical specimen's profiles. Calculated errors of those profiles are between 6 $\%$ to $11 \%$ in this case. The value of error is in middle range. Of course, it could be smaller but method used in the investigation of Johnson-Cook equation constants is still in experimental phase and need more time to check all variants.

\section{Summary}

Experimental results were used to determine dynamic yield stresses as well as constants of Johnson-Cook
Table 6. Model constants of Johnson-Cook equation for Al6063 duralumin.

\begin{tabular}{|c|c|}
\hline Constant & Value \\
\hline $\mathrm{A}$ & $111,82 \mathrm{MPa}$ \\
\hline $\mathrm{B}$ & $241,40 \mathrm{MPa}$ \\
\hline $\mathrm{n}$ & 0,415 \\
\hline $\mathrm{C}$ & 0,012 \\
\hline $\mathrm{m}$ & 1,003 \\
\hline
\end{tabular}

equation for A16063 duralumin. Determined averaged dynamic yield stress for this material is $Y=231 \mathrm{MPa}$ and is higher than static yield stress in compression $\mathrm{R}_{0,2}=$ $160 \mathrm{MPa}$ and then tensile strength $R_{\mathrm{m}}=215 \mathrm{MPa}$. It shows that Al6063 duralumin is strain rate sensitive material.

Experimental results were also used to identify model constants of Johnson-Cook equation with the application of new idea of the identification method. This method presented in this paper is still under improving process. Obtained constants for Al6063 duralumin placed in Table 6 using this method are sufficient to next numerical simulations for example duralumin protective facades under dynamic loading.

\section{References}

1. J. Janiszewski, M. Grązka, Coordinate measuring technique in the study of dynamic properties of materials by Taylor impact test, Mechanik 1, 2011, 56, (in Polish).

2. J. Janiszewski, W. Koperski, J. Starczewski, E. Włodarczyk, Estimation of dynamic yield stress of shell steels by means of the Taylor impact test, Biul. WAT vol. LVI 1, 2007, 645, (in Polish).

3. G. Taylor, The use of flat-ended projectiles for determining dynamic yield stress 1. Theoretical considerations, Proc. Roy. Soc. London Series A. 1948.

4. M. Grazkka, Application of Taylor impact test for the determination of material constants of Johnson-Cook equation, Conference materials, TKI Bełchatów 2011, (in Polish).

5. J. Janiszewski, Results of laboratory experiments, Technical Report, Military University of Technology, Warsaw 2008 (in Polish, not published). 